The effects of perceived stress on hope in women with breast cancer and the role of

\title{
psychological hardiness.
}

\author{
Abbas Abdollahi ${ }^{a *}$, Hannaneh Panahipour ${ }^{a}$, Simin Hosseinian ${ }^{\text {a }}$, Kelly A. Allen ${ }^{\text {b }}$ \\ ${ }^{a}$ Department of Counseling, Faculty of Education and Psychology, Alzahra University, Tehran, \\ Iran \\ ${ }^{\mathrm{b}}$ Educational Psychology and Inclusive Education, the Faculty of Education, Monash University, \\ Clayton, Australia. \\ * Corresponding author: Abbas Abdollahi, Tel: 00989126585744, email:A.abdollahi@alzahra.ac.ir
}

\section{Abstract}

Objective: Diagnosis and treatment of breast cancer are psychologically stressful events, and hope and hardiness have been found to be important constructs for women with breast cancer. Therefore, this research sought to examine the relationships of perceived stress and hardiness with hope, and the buffering role of hardiness in the link between perceived stress and hope among Iranian women with breast cancer.

Methods: Two hundred and twenty Iranian women with breast cancer from three hospitals completed online measures evaluating perceived stress, hardiness, and hope.

Results: Using Structural Equation Modelling, perceived stress was found to be negatively related to hope. Additionally, there was a positive relationship between hardiness and hope. The findings indicate that hardiness is a buffer in the link between perceived stress and hope for women with breast cancer.

This is the author manuscript accepted for publication and has undergone full peer review but has not been through the copyediting, typesetting, pagination and proofreading process, which may lead to differences between this version and the Version of Record. Please cite this article as doi: $10.1002 /$ pon.5102

This article is protected by copyright. All rights reserved. 
Conclusions: These findings demonstrate the importance of hardiness in reducing the effects of perceived stress on hope and have clinical implications for health professionals.

\section{KEYWORDS:}

perceived stress, hardiness, hope, women with breast cancer, oncology, cancer, resilience, distress

\section{INTRODUCTION}

Breast cancer is the most prevalent cancer among adult females ${ }^{1}$. This illness may have negative effects on both physical and psychological wellbeing of breast cancer patients and their families ${ }^{1}$. It is reported that 1.5 million women annually are diagnosed with breast cancer and this is the leading cause of death among adult females worldwide ${ }^{1}$. It is predicted that around 15 million people will have breast cancer by $2020^{2}$. In Iran there are 6160 cases of individuals diagnosed with breast cancer and that the total number of mortalities from breast cancer is 1063 cases annually ${ }^{3}$.

Research has revealed that women with breast cancer can report a range of negative responses following diagnosis that include anger, anxiety related to death and fear of mastectomy, psychological distress, and self-imposed social devaluation that may lead to feelings of hopelessness ${ }^{4,5}$. Studies have shown that hope is an important construct for breast cancer patients to cope with the associated stressors and difficulties associated with the disease ${ }^{5,6}$. Hope is defined as the perceived capability and motivation to pursue and achieve the desired goals ${ }^{7}$. Research has found hope to be an important factor for maintaining a commitment to favorable goals and coping skills in women with breast cancer ${ }^{8}$. However, there is little knowledge of the variables associated with hope in women with breast cancer ${ }^{9,10}$. Therefore, this study aimed to explore the predictors of 
hope (such as perceived stress and hardiness), as well as the moderating role of hardiness in the relationship between perceived stress and hope among women with breast cancer.

Women with breast cancer are more likely to experience stress before being diagnosed with breast cancer, or during treatment ${ }^{11}$. In line with the cognitive-transactional model of stress ${ }^{12}$, one study has found a strong relationship between perceived stress and disturbed daily cortisol rhythm ${ }^{13}$. The transactional- cognitive model of stress ${ }^{12}$ provides a framework to understand perceived stress as a relationship between a person and their environment. For instance, a person may consider an environment as harmful or a threat, which may present as challenges that influence the process of thoughts, feelings, emotions, and behaviors. On the other hand, another person may perceive the same environment as an opportunity to learn and evaluate the situation as positive, controllable, and manageable. These differences affect the individual thoughts and feelings towards how manageable a situation is. If the perception of the person is that the stressful life event exceeds their cognitive capacity, it is possible that the experience will have a negative impact on their physical and psychological health. Research findings have demonstrated an inverse association between perceived stress and hope ${ }^{14-16}$. Accordingly, it can be assumed that women with breast cancer with high levels of perceived stress are more likely to experience low levels of hope than those with low levels of perceived stress.

In addition to examining the relationship between perceived stress and hope in women with breast cancer, this study aimed to develop a moderation model of hardiness (with three main components of challenge, commitment, and control) in relation to perceived stress and hope. It is possible that hardiness plays an important role in the link between perceived stress and hope. Hardiness helps individuals to cope with stressful life events and evaluate them as growth opportunities (challenges 
to overcome). Research has also found hardiness to facilitate an individual's belief that they can cope with stressful events, as opposed to engaging in renunciation and aversion (related to lack of commitment) ${ }^{17}$. Hardiness also facilitates the individual to be active in dealing with stressful life events rather than being passive (control) ${ }^{18,19}$. Therefore, hardiness may also have a moderating role between stress and hope. Individuals high in hardiness are more likely to perceive stressors as events that can be a positive challenge, growth opportunity, or controllable and this has been found to have a positive influence on an individual's reported hopefulness and also their perceived stress ${ }^{17,20}$. Hardiness is considered as an explanatory term, while resilience is considered as a descriptive one. Resilience is defined as a tendency in individuals to overcome problems and adversities to remain healthy under stressful conditions with the help of several external factors, such as family support, positive work environment, good nutrition, and good sleep. However, hardiness only relates to internal factors, including commitment (versus alienation), control (versus powerlessness) and challenge (versus need for security), which help individuals not only remain strong under stressful conditions, but also perform better under stressful situations ${ }^{21,22}$. Studies have shown that individuals with high levels of hardiness are more likely to employ effective coping strategies to deal with problems, compared to those with low levels of hardiness ${ }^{23,24}$. Previous studies have found hardiness to be a moderator in the links between problem-solving skills ${ }^{17}$ and hopelessness ${ }^{25}$ with suicidal ideation for Malaysian undergraduate students who experience suicidal ideation. The purpose of this study is to explore the moderating role of hardiness in the link between perceived stress and hope among women with breast cancer. The findings from this study could inform preventive and therapeutic modalities for women with breast cancer. 
The present study hypothesized: (1) a negative association between perceived stress and hope, and (2) that hardiness could be a moderator between perceived stress and hope among women with breast cancer.

\section{METHODS}

\section{Participants}

We emailed questionnaires to 410 prospective participants, while we received 240 acceptable completed questionnaires (20 participants were considered as outliers because showing a Mahalanobis distance was significant at the level of $<.05^{26}$ ). So participants of this study were 220 women with breast cancer (including women who had experienced biopsy or mastectomy) from three hospitals in Tehran, Iran (Mean age= $46.23 \pm 8.8$, aged range from 26-61). For structural equation modelling studies, Kline ${ }^{27}$ suggested that 200 sample size is sufficient to ascertain that there was an adequate power for the proposed structural equation modelling. For the real study, nearly $10 \%$ more of the required sample size was added to sample for incomplete or unusable questionnaires. Therefore, the total number of participants for this study was 220 .

As shown in Table 1, $80 \%$ of the participants had invasive ductal carcinoma $(n=176), 9 \%$ had lobular carcinoma $(n=20), 6 \%$ had medullary carcinoma $(n=13), 4 \%$ had comedo-carcinoma $(n=8)$, and $1 \%$ had tubular carcinoma $(n=3)$. In terms of marital status, about $95 \%(n=209)$ of the women were married and the other $5 \%$ were single $(n=11)$. In terms of employment status, about $54 \%$ $(n=118)$ of the women were full time employees, $14 \%(n=31)$ of women were part time employees, and $32 \%(n=71)$ of women were homemakers. The questionnaires were filled out on average three months after the initial diagnosis of breast cancer. 


\section{Procedure}

Following ethics approval from the Iranian Ministry of Health and Medical Education (Code number: IR.MUI.REC.1396.1.45), and three hospitals in Tehran, a list of breast cancer patients and email addresses were provided to the lead researcher. Data were collected over a 2-month period from May 8, 2018 to July 19, 2018. A plain language statement outlining the details of the study, alongside a consent form (participants signed a consent form prior to completing the questionnaires) and questionnaires were emailed to prospective participants (there was no incentive to complete the questionnaires). Participants were informed that the survey would take approximately 25 minutes to complete and they had the right to withdraw at any time. Inclusion criteria was applied to participant selection. All participants were required to have a diagnosis of breast cancer by breast specialists in each hospital. All participants of the study were required to have basic literacy skills in order to complete the questionnaire independently. All participants recruited for the study completed the online consent form and questionnaire.

\section{Measures}

Hardiness was measured using the Personal Views Survey, Third Edition Revised; PVS III ${ }^{16}$. The PVS III-R is an eighteen-item self-report scale with 4-point Likert scale from 0 (not at all true) to 3 (very true). The standard procedure for scoring hardiness is to combine the three subscales of hardiness (commitment, control, and challenge) and obtain an overall score. Several studies reported suitable Cronbach's alpha values for the PVS II-R ${ }^{28,29}$. The average variance extracted and construct reliability for the PVS III-R are reported in Table 2.

Perceived stress was measured using the Perceived Stress Scale; PSS ${ }^{30}$. The PSS is a ten-item selfreport scale with 4-point Likert scale from 1 (never) to 5 (very often). The common method of 
scoring is reversing four items and tallying the items to obtain an overall score. Acceptable Cronbach's alpha values for the PSS have been reported in previous studies ${ }^{24,31}$. The average variance extracted and construct reliability for the PSS are reported in Table 2.

Hope was measured using the Herth Hope Scale; HHS ${ }^{32}$. The HHS is a thirty-item selfadministered instrument with 4 possible answers from 1 (Never applies to me) to 4 (Often applies to me). This scale comprises of three components: (a) Temporality and future, (b) Positive readiness and expectancy, and (3) interconnectedness. The standard method for scoring hope is to combine three components of hope to obtain an overall score. Several studies reported an acceptable reliability for the HHS ${ }^{32,33}$. The average variance extracted and construct reliability for the HHS are reported in Table 2 .

\section{Statistical Method}

Descriptive analysis showed that the range of missing values for items were between $.51 \%$ to 1.34\%. Therefore, for treating missing values an expectation maximization procedure in SPSS 24.0 software was used. Normality analysis in AMOS 23 software showed that the data did not deviate from the normal distribution assumption because values of skewness (-1.03 to 1.23) and kurtosis (1.41 to 1.97 ) were between \pm 2 and \pm 7 , respectively ${ }^{34}$.

\section{RESULTS}

\section{Descriptive Statistics and Preliminary Analyses}

Table 2 shows bivariate correlations, means, standard deviations, average variance extracted values and construct reliabilities for the study variables. The results of a Pearson correlation analysis indicated that hardiness $(\mathrm{r}=.65, p<.01)$ was positively correlated with hope, and perceived stress was negatively correlated with hardiness $(\mathrm{r}=-.56, p<.01)$ and hope $(\mathrm{r}=-.42, p<.01)$. 
[Insert “Table 2.”]

\section{Measurement Model Fit}

Kline 27 indicated that when the values of Goodness-of-Fit Index (GFI), Tucker-Lewis Index (TLI), and Comparative-Fit Index (CFI) exceed .90, the value of Root Mean Squared Error of Approximation (RMSEA) is below 0.08, and Chi Square (CMIN/DF) value is lower than 5; the model fits sufficiently. The measurement model in this study comprises of hardiness, hope, and perceived stress, and the measurement model analysis suggested a good fit for the data: CMIN/DF $($ Chi-square $)=3.11, \mathrm{p}<0.01, \mathrm{CFI}=0.92, \mathrm{GFI}=0.93, \mathrm{TLI}=0.92, \mathrm{RMSEA}=0.08$ with $90 \%$ confidence interval of 0.05 to 0.09 .

\section{Structural Model}

A structural model, as shown in Figure 1, comprises a set of exogenous variables (perceived stress and hardiness) and endogenous variable (hope) with the control variable of age. Structural model results showed that the model fit the data sufficiently $(\mathrm{CMIN} / \mathrm{DF}=3.09, \mathrm{CFI}=0.91, \mathrm{GFI}=0.90$, TLI=0.91, and RMSEA $=.08$ ).

Structural model results, as shown in Figure 1 , showed that hardiness $(\beta=.51, p<.01)$ was positively related to hope, and perceived stress $(\beta=-.32, p<.01)$ was negatively related to hope. The results showed a negative relationship between hardiness and perceived stress $(\beta=-.38, p<$ .01). Perceived stress and hardiness explained $39 \%$ of the variance of hope among women with breast cancer.

[Insert Figure 1] 
Perceived Stress, Hope, and Hardiness

\section{Moderation Test of Hardiness}

To explore the moderating role of hardiness in the link between perceived stress and hope, a multigroup analysis in SEM was employed. To do this, the data were segregated by the median split (median value of hardiness: 21.58$)$ in two groups: low hardiness group $(n=125)$ and high hardiness group $(n=95)$.

In the first step, the unrestricted model and the restricted model were compared based on the measurement fit indices, and the results showed that the unrestricted model $(\chi 2=29.71$, RMSEA $=$ $.053, \mathrm{CFI}=.90, \mathrm{GFI}=.90, \mathrm{NFI}=.90)$ was better than the restricted model $(\chi 2=51.15, \mathrm{RMSEA}=$ $.089, \mathrm{CFI}=.76, \mathrm{GFI}=.87, \mathrm{NFI}=.82$ ), because the chi-square value for the unrestricted model was smaller and other indices for the unrestricted model were greater than the restricted model. Thus, hardiness moderated the relationship between perceived stress and hope.

In the second step, the significance level of the individual paths of perceived stress and hope between the high hardiness group and the low hardiness group must be checked so that the standardized coefficient for one group is significant and for another group is not significant ${ }^{35}$.

The findings showed that women with breast cancer from the high hardiness group with high perceived stress scores were more likely to experience hope $(\beta=-.07, p=.07)$ than women with breast cancer from the low hardiness group $(\beta=-.35, p<.001)$.

\section{Moderation Test of Stages of Breast Cancer}

Multi group analysis showed that the stages of breast cancer did not have moderating effect in the proposed model, because the chi square value in the restricted model was greater than the unrestricted model. 
Perceived Stress, Hope, and Hardiness

CONCLUSIONIn line with the findings from previous research ${ }^{17}$, the findings from structural modelling indicated an inverse association between perceived stress and hope among women with breast cancer. One potential interpretation for this finding is that perceived stress may impede positive thought and positive emotions, and as a consequence, diminish hope. According to the cognitive-transactional stress theory ${ }^{12}$, one's perception about a stressful situation influences their ability to cope with stress. This theory states that negative beliefs affect the appraisal of situations and make meaning for reality. Beliefs about hope seem to be related to beliefs about stress. If beliefs of stress influence the perception of the situation as fearful or changeable, it affects hope. Women with breast cancer who report stress are more likely to have less hope toward their future.

The results from multi-group analysis indicated that hardiness moderated the effects of perceived stress on hope. The results revealed that hardiness was one of the most significant variables against stress, which means that women with breast cancer with high levels of hardiness were more likely to experience hope - even at the highest levels of perceived stress. The findings from this study support the findings of previous work that has illustrated that hardiness allows individuals to cope better with stress. These individuals may engage in a number of strategies, such as reframing the possible stressor into something that is positive or manageable, accepting that stress occurs in life, managing emotions by adopting helpful coping strategies (i.e., engaging in a pleasurable activity), committing to the process and goal of managing stressful events, and feeling internal control in the face of stressful demands ${ }^{28}$. Hardiness also enables individuals to cope with stresses by maintaining perseverance for long-term goals, keeping increasing performance under time pressure, and retaining effort despite difficulties and adversities ${ }^{28}$. 


\section{Study Limitations}

The study sample is restricted to Iranian women with breast cancer, and caution should be taken with generalizing the outcomes to other populations. The data for this study was collected during one time point and to better understand the relationships between hope, stress and hardiness, longitudinal designs or time series design are necessary and should be considered for future research.

\section{Clinical Implications}

The findings demonstrate the important role of hardiness in increasing hope among women with breast cancer despite the high levels of stress they experience. Therefore, the accurate assessment of perceived stress and hardiness in women with breast cancer is essential for psychologists, nurses, and clinicians. It has been thoroughly demonstrated that a sense of hopefulness plays a key role in recovery and treatment of women with breast cancer ${ }^{8}$. Therefore, it is plausible that interventions that increase hardiness in women with breast cancer may increase their hope and ability to manage stress. So far, several studies have been conducted on the efficacy of HardiTraining Program on the hardy attitudes and skills of high-risk college students ${ }^{36}$, high-risk undergraduate students ${ }^{37}$, nurses 38, and managers ${ }^{39}$. HardiTraining Program includes narratives on hardiness, inspirational examples, exercises, relaxation, and periodic checkpoints. Its emphasis is on exercising and developing the hardy skills of coping and self-care, and using the feedback obtained through these efforts to deepen the hardy attitudes of commitment, control, and challenge ${ }^{36}$. Future studies could explore the efficacy of HardiTraining Program on hope and hardiness of women with breast cancer.

\section{CONFLICT OF INTEREST}

All authors declare that they have no conflicts of interest. 


\section{FUNDING SOURCE FOR THE STUDY}

No financial support has been received for this study.

\section{DATA AVAILABILITY STATEMENT ${ }^{40}$}

The data that support the findings of this study are openly available in figshare at https://figshare.com/s/800f03cfbf33b5ec262d, reference number 10.6084/m9.figshare.8045330 40

\section{ORCID}

\section{Abbas Abdollahi http://orcid.org/0000-0002-8346-5043}

\section{REFERENCES}

1. Hasson-Ohayon I, Braun M, Galinsky D, Baider L. Religiosity and hope: A path for women coping with a diagnosis of breast cancer. Psychosomatics. 2009;50(5):525-533.

2. Radice D, Redaelli A. Breast cancer management. Pharmacoeconomics. 2003;21(6):383396.

3. Otaghvar HA, Hosseini M, Tizmaghz A, Shabestanipour G, Noori H. A review on metastatic breast cancer in Iran. Asian Pacific Journal of Tropical Biomedicine. 2015;5(6):429-433.

4. Mansano-Schlosser TC, Ceolim MF, Valerio TD. Poor sleep quality, depression and hope before breast cancer surgery. Applied Nursing Research. 2017;34:7-11.

5. Holst-Hansson A, Idvall E, Bolmsjö I, Wennick A. Hoping to reach a safe haven - Swedish families' lived experience when a family member is diagnosed with breast cancer. European journal of oncology nursing 
2017;31(May):52-58. doi:10.1016/j.ejon.2017.10.003.

6. Kashani FL, Vaziri S, Esmaeil Akbari M, Zeinolabedini N, Sanaei H, Jamshidifar Z. The Effectiveness of Creating Hope on Distress of Women with Breast Cancer. Procedia - Social and Behavioral Sciences. 2014;159:201-205. doi:10.1016/j.sbspro.2014.12.357.

7. C. R. Snyder. Hope Theory

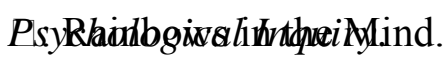
2014;13(4):249-275.

8. Schjolberg TK, Dodd M, Henriksen N, Rustoen T. Factors affecting hope in a sample of fatigued breast cancer outpatients. Palliative \& supportive care. 2011;9(1):63-72.

9. Afrooz R, Rahmani A, Zamanzadeh V, et al. The nature of hope among Iranian cancer patients. Asian Pac J Cancer Prev. 2014;15(21):9307-9312.

10. Abdullah-zadeh F, Agahosseini S, Asvadi-Kermani I, Rahmani A. Hope in Iranian cancer patients. Iranian journal of nursing and midwifery research. 2011;16(4):288.

11. Jang M, Kim J. A structural model for stress , coping, and psychosocial adjustment $\square$ : A multi-group analysis by stages of survivorship in Korean women with breast cancer. European Journal of Oncology Nursing. 2018;33(May 2017):41-48. doi:10.1016/j.ejon.2018.01.004.

12. Lazarus RS, Folkman S. Stress, Appraisal, and Coping. New York, Springer Publishing Company; 1984.

13. Lovell B, Moss M, Wetherell MA. Perceived stress, common health complaints and diurnal patterns of cortisol secretion in young, otherwise healthy individuals. Hormones and 
behavior. 2011;60(3):301-305.

14. Folkman S. Stress, coping, and hope. In: Psychological Aspects of Cancer. Springer; 2013:119-127.

15. Hirsch JK, Sirois FM. Hope and fatigue in chronic illness: The role of perceived stress. Journal of health psychology. 2016;21(4):451-456.

16. Wonghongkul T, Moore SM, Musil C, Schneider S, Deimling G. The influence of uncertainty in illness, stress appraisal, and hope on coping in survivors of breast cancer. Cancer Nursing. 2000;23(6):422-429.

17. Abdollahi A, Hosseinian S, Zamanshoar E, Beh-Pajooh A, Carlbring P. The moderating effect of hardiness on the relationships between problem-solving skills and perceived stress with suicidal ideation in nursing students. Studia Psychologica. 2018;60(1):30-41. doi:10.21909/sp.2018.01.750.

18. Maddi SR, Harvey RH, Khoshaba DM, Lu JL, Persico M, Brow M. The personality construct of hardiness, III: Relationships with repression, innovativeness, authoritarianism, and performance. Journal of Personality. 2006;74(2):575-598. doi:10.1111/j.14676494.2006.00385.x.

19. Maddi SR. The story of hardiness: Twenty years of theorizing, research, and practice. Consulting Psychology Journal: Practice and Research. 2002;54(3):173.

20. Abdollahi A, Talib MA, Yaacob SN, Ismail Z. Problem-Solving Skills Appraisal Mediates Hardiness and Suicidal Ideation among Malaysian Undergraduate Students. Plos One. 2015;10(4):1-14. doi:10.1371/journal.pone.0122222. 
21. Bartone PT, Eid J, Hystad SW. Training hardiness for stress resilience. Military psychology: Concepts, trends and interventions. 2016:231-248.

22. Sandvik AM, Hansen AL, Hystad SW, Johnsen BH, Bartone PT. Psychopathy, anxiety, and resiliency-Psychological hardiness as a mediator of the psychopathy-anxiety relationship in a prison setting. Personality and Individual Differences. 2015;72:30-34.

23. Bartone PT, Johnsen BH, Laberg JC. Hardiness, avoidance coping, and alcohol consumption in war veterans Stressmadefhededth. mediation study. 2016;(July):1-10. doi:10.1002/smi.2734.

24. Abdollahi A, Talib MA, Carlbring P, Harvey R, Yaacob SN, Ismail Z. Problem-solving skills and perceived stress among undergraduate students: The moderating role of hardiness. Journal of Health Psychology. 2016:1359105316653265.

25. Abdollahi A, Hosseinian S, Nooripour R, Najafi M. Clarifying the Roles of Hardiness and Hopelessness in Relation to Suicidal Ideation Among Malaysian Undergraduate Students. Practice in Clinical Psychology. 2017;5(4):243-250.

26. Tabachnick BG, Fidell LS. Using Multivariate Statistics (5th Ed). Allyn \& Bacon/Pearson Education; 2007.

27. Kline RB. Principles and Practice of Structural Equation Modeling (3rd Edn). Guilford Press; 2005. http://books.google.com.my/.

28. Abdollahi A, Abu Talib M. Hardiness, spirituality, and suicidal ideation among individuals with substance abuse: The moderating role of gender and marital status. Journal of Dual Diagnosis. 2015;11(1). doi:10.1080/15504263.2014.988558. 
29. Abdollahi A, Talib MA, Yaacob SN, Ismail Z. Emotional Intelligence, Hardiness, and Smoking: Protective Factors Among Adolescents. Journal of Child and Adolescent Substance Abuse. 2016;25(1). doi:10.1080/1067828X.2013.872070.

30. Cohen S, Kamarck T, Mermelstein R. A global measure of perceived stress. Journal of Health and Social Behavior. 1983;24(4):385-396.

http://www.ncbi.nlm.nih.gov/pubmed/6668417.

31. Abdollahi A, Carlbring P, Khanbani M, Ghahfarokhi SA. Emotional intelligence moderates perceived stress and suicidal ideation among depressed adolescent inpatients. Personality and Individual Differences. 2016;102:223-228. doi:10.1016/j.paid.2016.07.015.

32. Kaye Herth RN. Development and refinement of an instrument to measure hope. Research and Theory for Nursing Practice. 1991;5(1):39.

33. Snyder CR, Sympson SC, Ybasco FC, Borders TF, Babyak MA, Higgins RL. Development and validation of the State Hope Scale. Journal of personality and social psychology. $1996 ; 70(2): 321$

34. Byrne BM. Structural Equation Modeling With AMOS: Basic Concepts, Applications, and Programming, Second Edition. (L. E. A. Publishers, Ed.). Routledge Academic; 2010. http://www.amazon.com/dp/0805863737.

35. Kline RB. Principles and Practice of Structural Equation Modeling. New York:The Guilford Press; 2010. http://books.google.com.my.

36. Maddi SR, Harvey RH, Khoshaba DM, Fazel M, Resurreccion N. Hardiness training facilitates performance in college. The Journal of Positive Psychology. 2009;4(6):566-577. 
doi:10.1080/17439760903157133.

37. Maddi SR, Khoshaba DM, Jensen K, Carter E, Lu JL, Harvey RH. Hardiness training for high-risk undergraduates. NACADA Journal. 2002;22(1):45-55.

38. Judkins S, Reid B, Furlow L. Hardiness training among nurse managers: Building a healthy workplace. The journal of continuing education in nursing. 2006;37(5):202-207.

39. Maddi SR. Hardiness training at Illinois bell telephone. Health promotion evaluation. 1987:101-115.

40. [Dataset] Abdollahi A, Panahipour H, Hosseinian S, Allen K; 2019; The effects of perceived stress on hope in women with breast cancer and the role of psychological hardiness; figshare; $10.6084 / \mathrm{m} 9$.figshare. 8045330

TABLE 1. Clinical and demographic data of patients with breast cancer

\begin{tabular}{|c|c|c|}
\hline Variable & Number & Percentage \\
\hline \multicolumn{3}{|c|}{ Types of breast cancer } \\
\hline Invasive ductal carcinoma & 176 & 80 \\
\hline Lobular carcinoma & 20 & 9 \\
\hline Medullary carcinoma & 13 & 6 \\
\hline Comedo-carcinoma & 8 & 4 \\
\hline Tubular carcinoma & 3 & 1 \\
\hline \multicolumn{3}{|c|}{ Breast cancer stage } \\
\hline Stage I & 130 & 59 \\
\hline Stage II & 62 & 28 \\
\hline Stage III & 26 & 12 \\
\hline Stage V & 2 & 1 \\
\hline
\end{tabular}




\begin{tabular}{lccc} 
& Marital status & & \\
Married & & 209 & 95 \\
Single & Education & 11 & 5 \\
& & 29 & 13 \\
Less than diploma & & 51 & 23 \\
Diploma & 98 & 36 \\
Bachelor & 36 & 16 \\
Master & & 6 & 3 \\
PHD & Employment status & 118 & 54 \\
\multicolumn{2}{l}{$\begin{array}{l}\text { Full time employee } \\
\text { Part time employee }\end{array}$} & 31 & 14 \\
Homemaker & 71 & 32 \\
\hline
\end{tabular}

TABLE 2. Bivariate correlations, means, standard deviations, average variance extracted and construct reliability

\begin{tabular}{lccc}
\hline & 1 & 2 & 3 \\
\hline (1) Hardiness & 1 & $-.56^{* *}$ & $.65^{* *}$ \\
(2) Perceived stress & & 1 & $-.42^{* * *}$ \\
(3) Hope & & & 1 \\
Mean & 29.57 & 22.21 & 81.19 \\
Standard Deviation & 4.72 & 5.32 & 9.35 \\
Average Variance Extracted & .66 & .61 & .67 \\
Construct Reliability & .76 & .75 & .78 \\
\hline
\end{tabular}

**. Correlation is significant at the 0.01 level. 
Perceived Stress, Hope, and Hardiness

This article is protected by copyright. All rights reserved. 


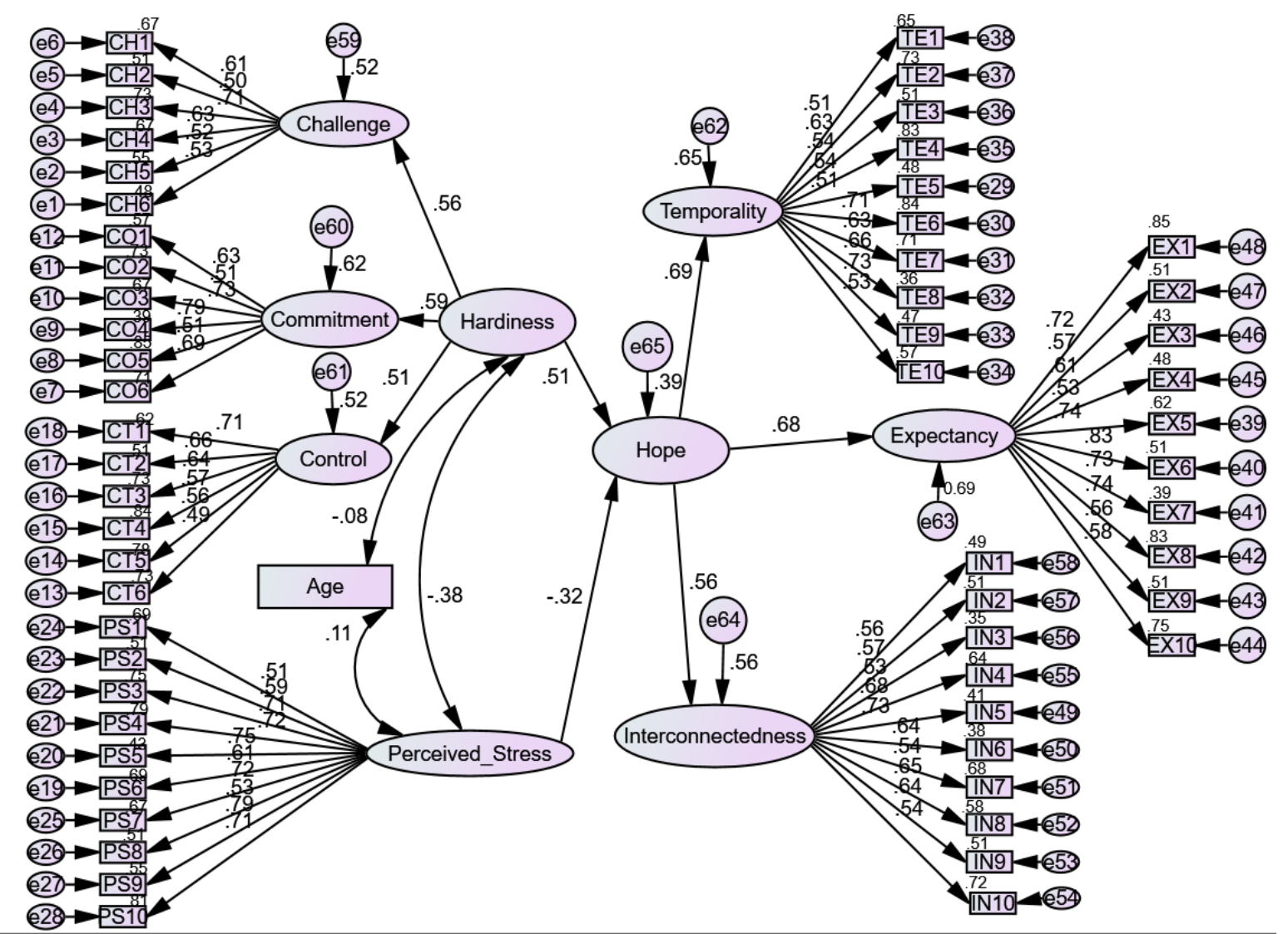

FIGURE 1. Structural model for the hope.

Age was chosen as a control variable. 


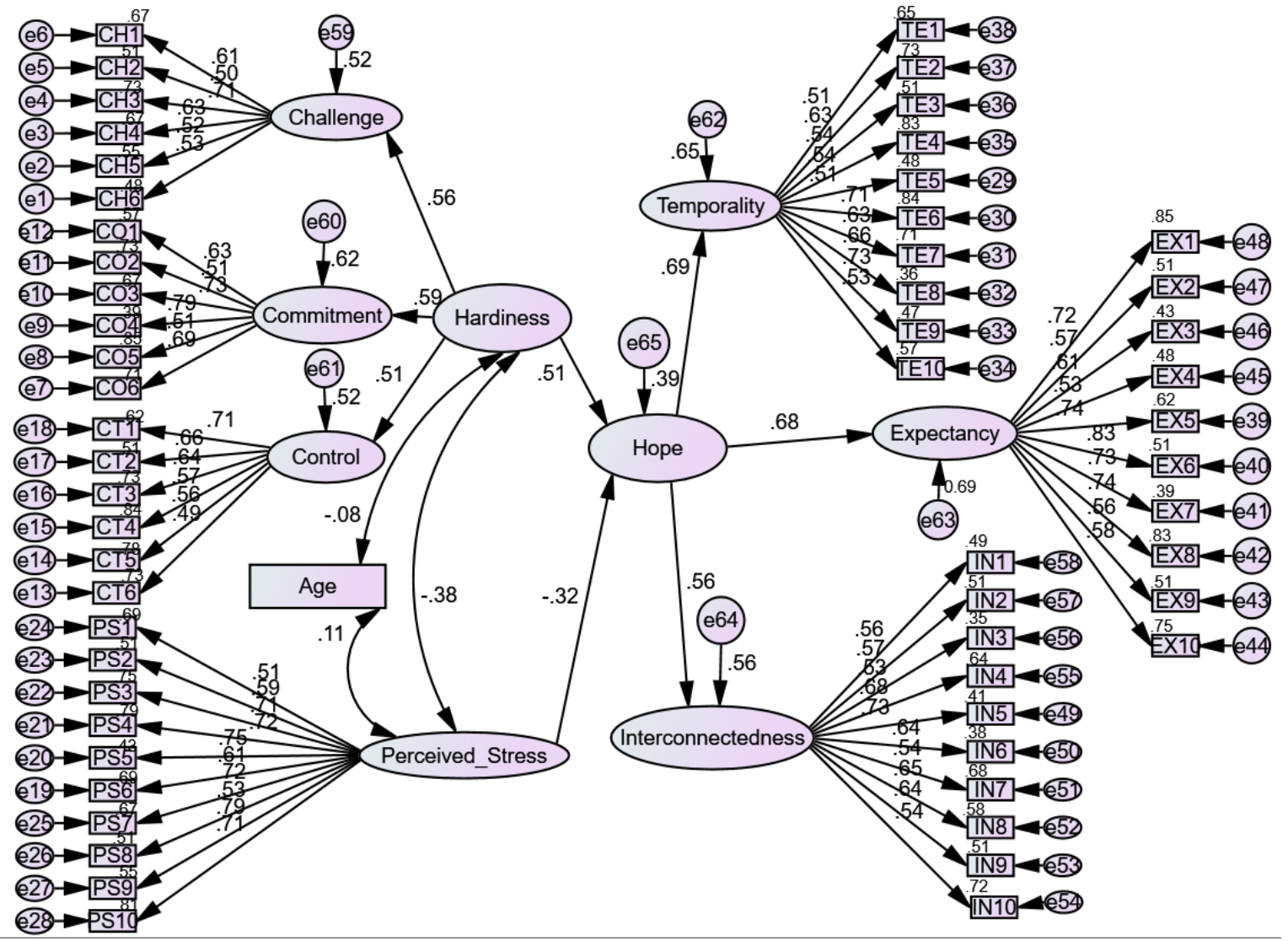

FIGURE 1. Structural model for the hope.

Age was chosen as a control variable. 


\section{University Library}

\section{- M M N E R VA A gateway to Melbourne's research publications}

Minerva Access is the Institutional Repository of The University of Melbourne

Author/s:

Abdollahi, A;Panahipour, H;Hosseinian, S;Allen, KA

Title:

The effects of perceived stress on hope in women with breast cancer and the role of psychological hardiness

Date:

2019-07-01

Citation:

Abdollahi, A., Panahipour, H., Hosseinian, S. \& Allen, K. A. (2019). The effects of perceived stress on hope in women with breast cancer and the role of psychological hardiness.

PSYCHO-ONCOLOGY, 28 (7), pp.1477-1482. https://doi.org/10.1002/pon.5102.

Persistent Link:

http://hdl.handle.net/11343/285962 